\title{
The proportion hyperhomocysteinemia in chronic kidney disease patients
}

\author{
Rizaldy Taslim Pinzon ${ }^{1,2}$, Rosa De Lima Renita Sanyasi ${ }^{3}$, Esdras Ardi Pramudita ${ }^{3}$ \\ ${ }^{1}$ Duta Wacana Christian University School of Medicine, Indonesia, ${ }^{2}$ Bethesda Hospital, Yogyakarta, Indonesia, \\ ${ }^{3}$ Panti Rapih Hospital, Yogyakarta, Indonesia
}

Background: Chronic kidney disease (CKD) patients often have a high homocysteine level Hyperhomocystinemia considered as one of cardiovascular disease risk factor in CKD patients. Studies concern on the proportion of hyperhomocysteinemia in patients with CKD in Indonesia are very limited. Aims and Objectives: The main objective was to identify the proportion of hyperhomocysteinemia in CKD patients. Materials and Methods: This was a cross sectional study. Subjects in this study were CKD patients with routine hemodyalisis two times per week. Five mililiters venous blood was collected before the first hemodyalisis. The blood was stored into tubes contain clot activator. Homocysteine level higher than $15.39 \mu \mathrm{mol} / \mathrm{L}$ considered as hyperhomocysteine. Results: Total of 122 subjects included at this study. Subjects dominated by male with mean age of 51.7 years. Anemia $(86.9 \%)$ and hypertension (86.1\%) were the common comorbidities. Co-treatment assessed in this study i.e.: folic acid, calcium carbonat, antihypertensive agent, antidiabetic agent, antiplatelet agent, lipid lowering agent, and hematopoietic agent. The prevalence of hyperhomocysteinemia was high $(89.3 \%)$ despite of the high consumption of folic acid in subjects $(86.1 \%)$. Conclusion: Hyperhomocysteinemia is a common condition among CKD patients with hemodyalisis.

\section{Access this article online}

Website:

http://nepjol.info/index.php/AJMS

DOI: 10.3126/ajms.v11i2.26433

E-ISSN: 2091-0576

P-ISSN: 2467-9100

Key words: Chronic kidney disease; Hyperhomocysteinemia; Vitamin B combination;

Cardiovascular disease

\section{INTRODUCTION}

Chronic kidney disease (CKD) defined as structural and functional disfunction and/or decreasing in glomerulus filtration $<60 \mathrm{~mL} /$ minutes $/ 1.73 \mathrm{~m}^{2}$ that lasting for more than 3 months. ${ }^{1} \mathrm{CKD}$ is a major health problem for the countries of Southeast Asia, including Indonesia. ${ }^{2}$ As the growing elderly population and increasing numbers of patients with diabetes and hypertension, the numbers of CKD patients will continue to rise and primary care practitioners will be confronted with management of the complex medical problems unique to patients with $\mathrm{CKD}{ }^{3}$

The risk for cardiovascular disease (CVD) morbidity and mortality remains high in all stages of $\mathrm{CKD},{ }^{4}$ including in patients with hemodialysis. ${ }^{5,6}$ More patients with CKD die of CVD than of the progression of kidney failure. ${ }^{7}$ The increase of homocysteine level, referred as hyperhomocysteinemia, is highly prevalent in CKD patients $^{8}$ and associated with an increased risk of CVD complications. ${ }^{9-11}$

Homocysteine, a sulfur amino acid, is the only direct precursor for 1-methionine synthesis. ${ }^{12}$ Hyperhomocysteinemia can also arise from nutritional deficiencies of folate, vitamin $\mathrm{B}_{6}$, and vitamin $\mathrm{B}_{12}{ }^{13}$ Folic acid, vitamin $\mathrm{B}_{6}$, and $\mathrm{B}_{12}$ are essential cofactors in homocysteine-methionine metabolism. Therefore, low vitamin $\mathrm{B}$ availability $\left(\mathrm{B}_{6}, \mathrm{~B}_{12}\right.$ and folic acid) impaired re-methylation of homocysteine to methionine and leads to homocysteine accumulation. ${ }^{14}$ Vitamin deficiency (including vitamin $\mathrm{B}_{1}, \mathrm{~B}_{6}, \mathrm{~B}_{12}$, and folic acid) are common in people with advanced renal failure who do not take nutritional supplements. ${ }^{15,16}$ This factor thought to be one of the reason of the high prevalence oh hyperhomocysteinemia in CKD patients.Studies 
concern on the proportion of hyperhomocysteinemia in patients with CKD in Indonesia are very limited. The objective of this study is to identify the proportion of hyperhomocysteinemia in $\mathrm{CKD}$ patients.

\section{MATERIALS AND METHODS}

The method of this study was a cross sectional study conducted at Bethesda Hospital and Panti Rapih Hospital, Yogyakarta, Indonesia from August to September 2018. Each subject would be followed for 4 weeks.

After sample calculation, the minimum subjects requirement were 120 subjects. Inclusion criteria i.e.: male or female, age $>18$ years, diagnosed with CKD. Each subject undergo a routine hemodyalisis two times per week (describe as "first hemodyalisis" and "second hemodyalisis" for the sequence of hemodyalisis per week) with time interval between each hemodyalisis was 3 to 4 days. Exclusion criteria i.e.: did not willing to join the study, participation in other clinical trial in the last 1 month, incompetent to give a consent and to answer the questionnaires, pregnant or has a plan to get pregnant.

Variables assessed in this study i.e.: demographic data, medical history, co-treatment, homocysteine level, and the presence of adverse event. Demographic data includes: age, gender, marriage status, educational degree, and occupation. Five mililiters venous blood was collected before the first hemodyalisis. Blood collection was done by nurse in hemodyalisis center and tested by laboratory technician in a certified laboratory. The blood was stored into tubes contain clot activator. Homocysteine level higher than $15.39 \mu \mathrm{mol} / \mathrm{L}$ considered as hyperhomocysteine.Subjects characteristics and the proportion of hyperhomocysteinemia were described in percentage.

\section{Ethical clearance}

Each subject participating in this study must signed an informed consent form. Informed consent process will be made very clearly. Each patient was freed to choose to be involved or not to be involved in this study. For those who refuse to be involved in this study are not required to explain their reason and will not affect their therapy.

The data used only for research. Patients identity will be classified. All document will be saved in study center after the study is completed. The research document will only be seen by the parties related to this research. This study was verified by Duta Wacana Christian University School of Medicine Ethical Research Committee with number of ethical clearance 614/C.16/FK/2018.

\section{RESULTS}

Total of 122 subjects included at this study, dominated by male with mean age of 51.7 years. Anemia $(86.9 \%)$ and hypertension (86.1\%) were the common comorbidities. Co-treatment assessed in this study i.e.: folic acid, calcium carbonat, antihypertensive agent, antidiabetic agent, antiplatelet agent, lipid lowering agent, and hematopoietic agent. Folic acid (86.1\%) and hematopoietic agent (82.8\%) were the common co-treatment. Table 1 shows the subjects' characteristics.

Figure 1 represent the proportion of hyperhomocysteinemia compared to normal homocysteine level. The prevalence of hyperhomocysteinemia was $89.3 \%$. Despite of the high consumption of folic acid, the proportion of hyperhomocysteinemia in CKD patients remains high.

\begin{tabular}{lcc} 
Table 1: Characteristics of subjects & \\
\hline Characteristics & $\begin{array}{c}\text { Number of } \\
\text { subjects (n=122) }\end{array}$ & \\
\hline Gender & & \\
Male & 78 & 63.9 \\
Female & 44 & 36.1 \\
Mean age & $51.7 \pm 12.6$ years & \\
Comorbidity & & \\
Hypertension & 105 & 86.1 \\
Diabetes Mellitus & 41 & 33.6 \\
Stroke & 9 & 7.4 \\
Cardiovascular disease & 32 & 26.2 \\
Congenital kidney disease & 2 & 1.6 \\
Urinary tract calculus & 9 & 7.4 \\
Urinary tract infection & 5 & 4.1 \\
Anemia & 106 & 86.9 \\
Dyslipidemia & 4 & 3.3 \\
Co-treatment & 105 & 86.1 \\
Folic acid & 84 & 68.9 \\
Calcium carbonat & 100 & 82 \\
Antihypertensive agent & 27 & 22.1 \\
Antidiabetic agent & 11 & 5.7 \\
Antiplatelet agent & 7 & \\
Lipid lowering agent & & \\
Hematopoietic agent & & \\
\hline
\end{tabular}

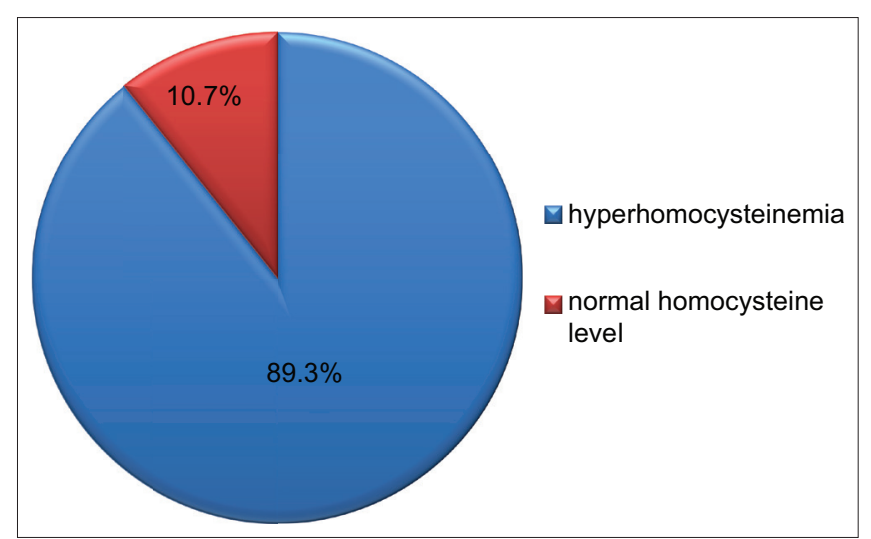

Figure 1: The proportion of hyperhomocysteinemia 


\section{DISCUSSION}

Hyperhomocysteinemia defined as homocysteine level higher than $15.39 \mu \mathrm{mol} / \mathrm{L}$. Hyperhomocysteinemia known as a common condition among CKD patients with hemodyalisis. ${ }^{17}$ This present study was also showed a high prevalence of hyperhomocysteinemia. The prevalence of hyperhomocysteine was $89.3 \%$. This result is similar to previous studies. Ciancolo, et al. (2017) stated hyperhomocysteinemia occurs in about $85 \%$ of CKD patients because of impaired renal metabolism and reduced renal excretion. ${ }^{18}$ This statement is in concordance with Long and Nie (2016). Homocysteine level in patients with end-stage of renal disease (ESRD) is 3 to 5 times higher than normal and the prevalence of hyperhomocysteinemia in this patient group is $85-100 \% .{ }^{19}$ A cross sectional study by Chen, et al. (2017) in patients with CKD stage 2 to 5 showed hyperhomocysteinemia was prevalent. Homocysteine levels were 2-fold higher in hemodialysis patients than those in early stage CKD. ${ }^{20}$ Cross sectional study included 1042 CKD patients showed the prevalence of hyperhomocysteinemia in CKD was increasing as the disease stage increase. The prevalence of hyperhomocysteinemia in CKD stage 1, stage 2, stage 3, stage 4 and stage 5 patients was $10.73 \%, 29.22 \%, 58.71 \%$, $75.23 \%$ and $83.75 \%$, respectively. ${ }^{21}$

CVD and stroke are the most common cause of death in the setting of ESRD. ${ }^{22}$ Individuals with stage 3 CKD are more likely to die from CVD than to progress to ESRD. ${ }^{23}$ One of the proposed mechanism of CVD in patients with $\mathrm{CKD}$ is the high homocysteine level. In a study on dialysis patients with and without CVD, serum homocysteine level was significantly high in patients with CVD compared to patients without accompanying CVD $(37.2 \mu \mathrm{mol} / \mathrm{L}$ versus $24 \mu \mathrm{mol} / \mathrm{L})$. In other study performed on 176 patients with ESRD, patients with a greater serum level of homocysteine had 2.9 times higher rates of atherosclerosis and thrombotic events. ${ }^{24}$

Hyperhomocysteinemia induce induces oxidative stress and antagonizes the vasodilator properties of nitric oxide, thus leading to endothelial dysfunction. Following oxidative stress, endothelial cells produce various cytokines participating in inflammatory reactions. ${ }^{18}$ Hyperhomocysteinemia activates metalloproteinases and induces collagen synthesis, leading to the reductionof vascular elasticity. ${ }^{25}$ Homocysteine was also proven to promote the proliferation of smooth muscle cells leading to several interactions with platelets, clotting factors, lipids, ${ }^{18}$ and indeed might contribute to the scavenger receptor-mediated uptake of oxidized-LDL by macrophages resulting in foam cell formation in atherosclerosis. ${ }^{26}$
Despite of the high consumption of folic acid, the proportion of hyperhomocysteinemia in CKD patients in this current study remains high. Proposed mechanisms for hyperhomocysteinemia in kidney failure include deficiencies of vitamin cofactors (pyridoxal 5'-phosphate/ PLP, an active form of vitamin $\mathrm{B}_{6}, \mathrm{~B}_{12}$, and folic acid $)^{19,27}$ and reduced clearance of total plasma homocysteine. ${ }^{28}$ The administration of vitamin $\mathrm{B}$, especially vitamin $\mathrm{B}_{6}$, vitamin $\mathrm{B}_{12}$, and folic acid, are potential to reduce homocysteine level. ${ }^{29-32}$

\section{CONCLUSION}

This study shows hyperhomocysteinemia is common among CKD patients with hemodyalisis. Hyperhomocysteinemia is a risk factor for CVD complication in CKD patients and is commonly associated with deficiencies of vitamins B. Supplementation of vitamin B in CKD patients is higly recommended.

\section{ACKNOWLEDGEMENT}

We would like to express our special thanks of gratitude to all subjects in this study. We would like to thanks to Ethical Committee of Duta Wacana Christian University School of Medicine for helping in the ethical clearance process. We also express our sincere thanks to Panti Rapih Hospital and Bethesda Hospital where this study was conducted.

\section{REFERENCES}

1. Kidney Disease: Improving Global Outcomes (KDIGO) CKD Work Group. Chapter 1: Definition and classification of CKD. Kidney International Supplements 2013;3: 19-62.

2. Jha V. Current status of chronic kidney disease care in Southeast Asia. Seminars in Nephrology 2009;29(5):487-497.

3. Thomas R, Kanso A and Sedor JR. Chronic Kidney Disease and Its Complications. Prim Care Clin Office Pract 2008;35:329-344.

4. Wright $J$ and Hutchison $A$. Cardiovascular disease in patients with chronic kidney disease. Vasc Health Risk Manag 2009;5:713-722.

5. Kobayashi S. Cardiovascular Events in Hemodialysis Patients: Challenging against Vascular Calcication. Ann Vasc Dis 2017;10(1):1-7.

6. Mavrakanas TA and Charytan DM. Cardiovascular complications in chronic dialysis patients. Curr Opin Nephrol Hypertens 2016;25(6):536-544.

7. Weiner DE. Causes and Consequences of Chronic Kidney Disease: Implications for Managed Health Care. J Manag Care Pharm 2007;13(3)(suppl):S1-S9.

8. Arnold R, Issar T, Krishnan AV and Pussell BA. Neurological complications in chronic kidney disease. Journal of the Royal Society of Medicine Cardiovascular Disease 2016;5:1-13.

9. Ashjazadeh N, Fathi M and ShariatA. Evaluation of Homocysteine Level as a Risk Factor among Patients with Ischemic Stroke and Its Subtypes. IJMS 2013:38(3):233-239. 
10. Checherita IA, Turcu F, Dragomirescu RF and Ciocalteu A. Chronic complications in hemodialysis: correlations with primary renal disease. Romanian Journal of Morphology and Embryology 2010;51(1):21-26.

11. Di Lullo L, House A, Gorini A, Santoboni A, Russo D and Ronco C. Chronic kidney disease and cardiovascular complications. Heart Fail Rev 2014 DOI 10.1007/s10741-014-9460-9

12. Manolescu BN, Oprea E, Farcasanu IC, Berteanu M and Cercasov C. Homocysteine and vitamin therapy in stroke prevention and treatment: a review. ABP 2010;57(4):467-477.

13. Curro M, Gugliandolo A, Gangemi C, Risitano R, lentile R and Caccamo D. Toxic effects of mildly elevated homocysteine concentrations in neuronal-like cells. Neurochem Res 2014;39:1485-1495.

14. Mangge H, Becker K, Fuchs D and Gostner JM. Antioxidants, inflammation and cardiovascular disease. World J Cardiol 2014; 6(6):462-477.

15. Mahajan SK and Aundhakar SC. A study of the prevalence of serum vitamin B12 and folic acid deficiency in Western Maharashtra. J Family Med Prim Care 2015;4:64-68.

16. Steiber AL and Kopple JD. Vitamin status and needs for people with stages 3-5 chronic kidney disease. Journal of Renal Nutrition 2011; 21(5):355-368.

17. Danis R, Ozmen S, Akin D, Celik F and Yazanel O. Predictive factors of cardiovascular disease in patients on maintenance. Hemodialysis Dyalisis \& Transplantation 2008;1-5.

18. Ciancolo G, De Pascalis A, Di Lullo L, Ronco C, Zannini C and La Manna G. Folic acid and homocysteine in chronic kidney disease and cardiovascular disease progression: which comes first? Cardiorenal Med 2017;7:255-266.

19. Long $Y$ and Nie J. Homocysteine in Renal Injury. Kidney Dis (Basel) 2016; 2(2):80-87.

20. Chen $\mathrm{CH}$, Yeh EL, Chen $\mathrm{CC}$, Huang SC and Huang YC. Vitamin B-6, Independent of Homocysteine, Is a Significant Factor in Relation to Inflammatory Responses for Chronic Kidney Disease and Hemodialysis Patients. BioMed Research International 2017; doi:7367831.

21. Ye Z, Zhang Q, Li Y, Wang C, Zhang J, Ma X, et al. High Prevalence of Hyperhomocysteinemia and Its Association with Target Organ Damage in Chinese Patients with Chronic Kidney
Disease. Nutrients 2016; 8(10):645.

22. Collins AJ, Foley RN, Chavers B, Gilbertson D, Herzog C, IshaniA, et al: US Renal Data System 2013 Annual Data Report. Am J Kidney Dis 2014;63(suppl).

23. McCullough PA, Steigerwalt $S$, Tolia $K$, et al: Cardiovascular disease in chronic kidney disease: data from the Kidney Early Evaluation Program (KEEP). Curr Diab Rep 2011;11:47-55.

24. Tamadon M, Jamshidi L, Solemani A, Ghorbani R, Malek F and Malek M. Effect of different doses of folic acid on serum homocysteine level in patients on hemodialysis. IJKD 2011;5:93-96.

25. Sen U, Mishra PK, Tyagi $N$ and Tyagi SC. Homocysteine to hydrogen sulfide or hypertension. Cell Biochem Biophys 2010;57:49-58.

26. Thampi P, Stewart BW, Joseph L, Melnyk SB, Hennings LJ and Nagarajan S. Dietary homocysteine promotes atherosclerosis in apoE-deficient mice by inducing scavenger receptors expression. Atherosclerosis 2008;197:620-629.

27. Curro M, Gugliandolo A, Gangemi C, Risitano R, lentile R and Caccamo D. Toxic effects of mildly elevated homocysteine concentrations in neuronal-like cells. Neurochem Res 2014;39:1485-1495.

28. Cozzolino M, Gentile G, Mazzaferro S, Brancaccio D, Ruggenenti $P$ and Remuzzi G. Blood pressure, proteinuria, and phosphate as risk factors for progressive kidney disease: a hypothesis. Am J Kidney Dis 2013; 62:984-992.

29. Markisic M, Pavlovic AM and Pavlovic DM. The impact of homocysteine, vitamin B12, and vitamin D levels on functional outcome after first-ever ischaemic stroke. Biomed Res Int 2017; DOI:2017/5489057.

30. Loland KH, Bleie O, Blix AJ, Strand E, Ueland PM, Refsum H, et al. Effect of homocysteine-lowering $b$ vitamin treatment on angiographic progression of coronary artery disease: A Western Norway B Vitamin Intervention Trial (WENBIT) substudy. Am J Cardiol 2010;105:1577-1584.

31. Terwecoren A, Steen E, Benoit D, Boon P and Hemelsoet. Ischemic stroke and hyperhomocysteinemia: truth or myth? Acta Neurol Belg 2009;109:181-188.

32. Gugun AM. Hiperhomosisteinemia dan Faktor Risiko KelainanVaskuler. Mutiara Media 2008;8(2):97-105.

Authors Contribution:

RTP: Concept and design of study, reviewed the literature, collected data, prepared first draft of manuscript; RDLRS: Concept and design of study, reviewed the literature, literature search, manuscript preparation, statistically analyzed and interpreted, revision of the manuscript; EAP: Concept and design of study, collected data, prepared first draft of manuscript

\section{Work attributed to:}

Duta Wacana Christian University School of Medicine, Indonesia

Orcid ID:

Rizaldy Taslim Pinzon - (D) https://orcid.org/0000-0002-3357-9907

Rosa De Lima Renita Sanyasi - (1) https://orcid.org/0000-0002-3616-6796

Esdras Ardi Pramudita - (1) https://orcid.org/0000-0002-6956-6921

Source of Support: Nil, Conflict of Interest: None declared. 